\title{
¿Colonos o montaraces? Territorialidades en las selvas fronterizas de Guatemala y México (siglos XVIII-XX)
}

\section{Settlers or Montaraces? Territorialities in the Guatemala and México Border (18th-20th Centuries) Colonos ou guardiões? Territorialidades nas florestas fronteiriças da Guatemala e do México (séculos XVIII- XX)}

\begin{abstract}
Rosa Torras Conangla*
Resumen: El texto analiza las modalidades de colonización vividas en la región transfronteriza conformada por el sur del Estado de Campeche -México- y norte del departamento de Petén - Guatemala - Fue una zona de refugio durante la Colonia que ha experimentado, hasta bien entrado el siglo XX, proyectos de colonización dirigidos a asentar a población migrante para fijar la frontera, rompiendo con territorialidades previas marcadas por la movilidad.

Palabras claves: historia; colonización; territorio; asentamiento humano; frontera; etnicidad, Guatemala; México.

Abstract: The text analyzes the colonization modalities experienced in the crossborder region formed by the south of the state of Campeche - Mexico - and the north of the department of Petén - Guatemala - It was a refuge area during the Colony that has experienced, until well into the 20th century, colonization projects aimed at settling the migrant population to fix the border, breaking with previous territorialities defined by mobility.
\end{abstract}

Keywords: history; colonization; territory; human settlement; frontier; ethnicity; Guatemala; México.

* Mexicana. Doctora en Estudios Mesoamericanos por la Universidad Nacional Autónoma de México (UNAM), México. Investigadora en el Centro Peninsular en Humanidades y Ciencias Sociales de la Universidad Nacional Autónoma de México (UNAM), Ciudad de México, México. Correo electrónico: mima638@gmail.com. ORCID: https://orcid.org/0000-0003-3459-7055. 
Resumo: O texto analisa as modalidades de colonização vivenciadas na região transfronteiriça formada pelo sul do estado de Campeche - México- e o norte do departamento de Petén — Guatemala—. Foi área de refúgio durante a Colônia que sofreu, até meados do século XX, projetos de colonização com o objetivo de assentar a população migrante para fixar a fronteira, rompendo com as territorialidades anteriores marcadas pela mobilidade.

Palavras chaves: história; colonização; território; assentamento humano; fronteira; etnia, Guatemala; México.

\section{Introducción}

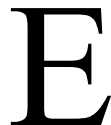

1 intrincado proceso de colonización del área maya creó la noción de la montaña entendida por la Corona hispana como la región cuya población escapaba a su control. Siguiendo la idea del monte comprendido como el hábitat disperso de los mayas - sinónimo de lo pagano y lo bárbaro - sobre el que había que imponer la congregación, se denominó la montaña a buena parte de las tierras bajas mayas, selváticas, que cubrían el sur y oriente de la península de Yucatán y el Petén convertidas en espacio de refugio de indios prófugos, apóstatas e insumisos. En el dificultoso avance de la frontera colonial, seguir su rastro nos perfila dónde, a lo largo del tiempo, iban quedando los espacios de resistencia indígena al poder colonial. A inicios del siglo XVII, la franja sur de la Península seguía siendo la montaña, vista como puerta de entrada para la conquista de los «indios montaraces» del Petén Itzá. ${ }^{1}$ Como bien reseña Julien Machault, siendo un área de intenso intercambio comercial, el establecimiento de la sociedad colonial en la montaña provocó grandes tensiones en las relaciones interétnicas que no fue considerada como «pacificada» sino hasta el siglo XVIII. ${ }^{2}$

Era una vasta región de bosque tropical lluvioso, articulada por un sistema hidrográfico que comprendía la cuenca del río Usumacinta y la del Candelaria, en la vertiente del Golfo de México, y la cuenca del río Hondo en la vertiente caribeña. Estaba habitada por chontales de Acalán, itzaes, kejaches y mopanes entre otros grupos, a quienes se unieron los mayas yucatecos huidos ya fuera del régimen colonial o, en pleno siglo XIX, de la Guerra de castas. Entre la Gobernación de Yucatán y la Audiencia de Guatemala, los asentamientos españoles se concentraron durante el siglo XVIII en las lagunas de los dos extremos de la región: por un lado, en la de Términos capitalizado por el presidio del Carmen en la Isla del mismo nombre y, por el otro, en el lago Petén Itzá, con el presidio de

1 Adriana Rocher Salas, «La vicaría de Chichanhá y la provincia franciscana de San José de Yucatán», en: Arte e historia en el sur colonial de Quintana Roo, siglos XVI-XVIII, (coord.) Juan Manuel Espinosa Sánchez (México: CONACULTA; Secretaría Cultura Quintana Roo; Plaza y Valdés, 2011), 98-108.

2 Julien Machault, «Organización y modalidad del intercambio a larga distancia en "la Montaña” del Petén, siglos XVI-XVII», Indiana, vol. 35, n. 1 (2018): 97-100, http://dx.doi.org/10.18441/ind.v35i1.97-120. 
Nuestra Señora de los Remedios que luego sería la ciudad de Flores. Los escasos pueblos de indios quedaron circundantes a ambos lagos; mientras los intentos de fundar asentamientos estables que mantuvieran abierto el Camino real para comunicar Flores con Mérida y Campeche, fueron poco exitosos.

Esta referencia histórica que puede parecer lejana, nos acerca a un atributo secular de estas selvas sobre el cual propongo reflexionar con una mirada de larga duración: frente al patrón de asentamiento disperso y en los montes propio de la sociedad maya, la permanente imposición de la política colonial de «reducción» que intentaba concentrar a la población en «casas juntas, trazadas en forma de pueblo» a lo largo de un camino en tiempos de colonización española ${ }^{3}$ y que, a modo de hipótesis, se ha mantenido en el tiempo como forma de colonialidad. Si en el imaginario colonizador el monte era el espacio bárbaro y pagano, para la población que lo habitaba era espacio de refugio o, mejor dicho, de resistencia.

La colonización asociada a la expansión del control territorial plasmado en la reducción de indios montaraces fue la herramienta básica en la dinámica territorial de las selvas, a pesar de fracasar reiteradamente en la política de formación de pueblos de indios. Con el avance de la frontera a lo largo del siglo XIX y la conformación de los Estados-nación, la colonización de las selvas, concebidas como despoblado - es decir, con población insumisa—, se fue asociando a la inmigración de manera que, dependiendo del estatuto de legitimidad otorgado a un tipo u otro de migrante, los Estados fueron ciñendo derechos y despojos. Cierta inmigración destinada a asentarse y ocupar el territorio fue vista como signo de progreso; mientras la movilidad de la población local sería asumida como atributo de bárbaros.

Nos situamos, entonces, en las selvas compartidas actualmente por el sur del estado mexicano de Campeche y el norte del departamento de Petén en Guatemala, espacio catalogado como DESPOBLADO en el siguiente mapa, de 1809, que cartografiaba la península de Yucatán, incluido el Petén.

3 Tsubasa Okoshi Harada, «De lo ajeno impuesto a lo nuestro fundado: el proceso de "domesticación” del espacio en los pueblos indios de la gobernación de Yucatán», en: Recorriendo el lindero, trazando la frontera, (coord.) Tsubasa Okoshi Harada, et al. (Ciudad de México, México: UNAM, 2018), 16-20. 


\section{Mapa 1. Mapa político de la provincia de Yucatán, 1809}

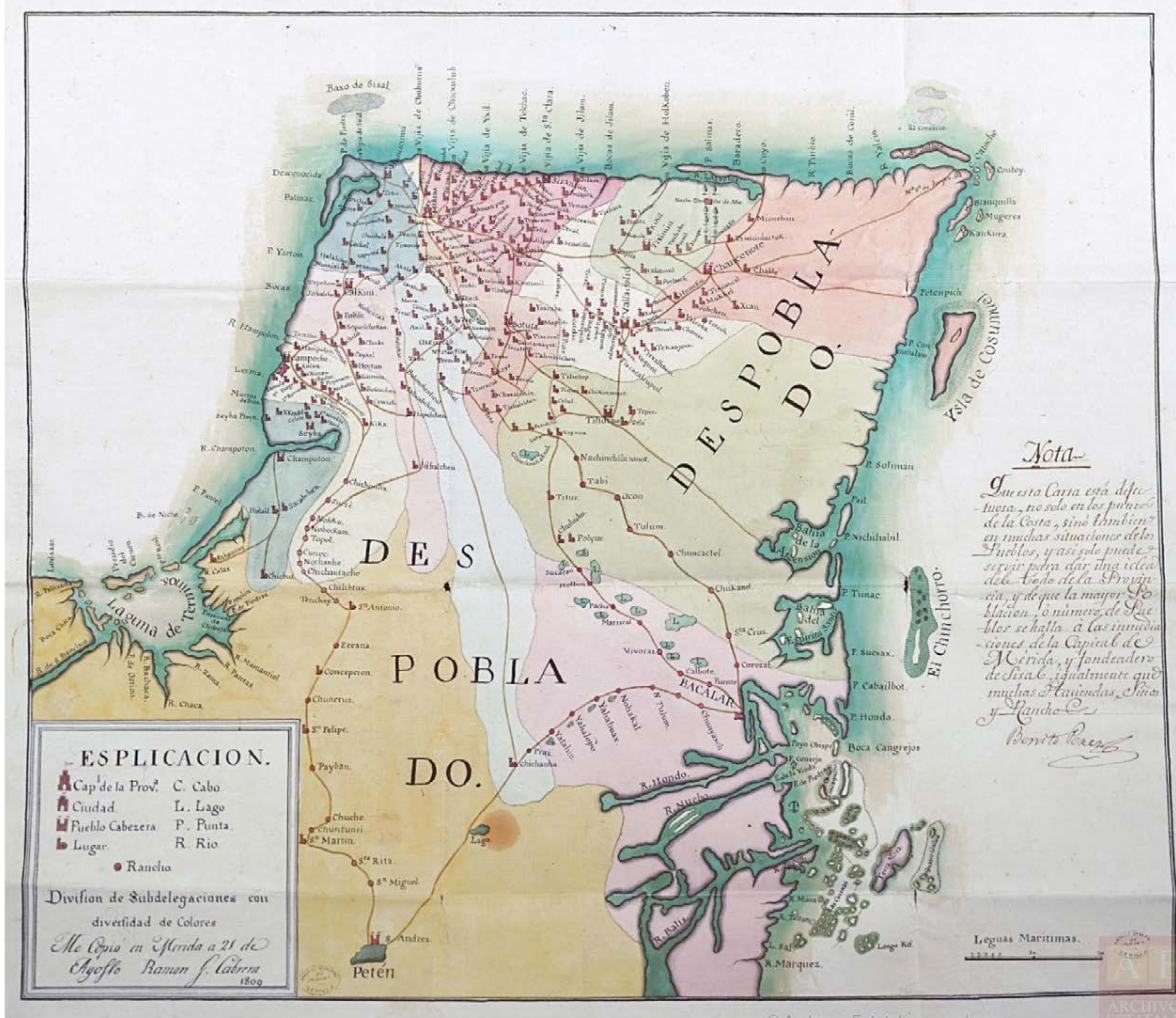

Fuente: «Mapa político de la provincia de Yucatán», 1809, Archivo General de Indias (PARES), MP-MÉXICO, 756.

En 1895, dicha área quedó definitivamente partida entre Guatemala y México por el paralelo $17^{\circ} 49^{\prime}$. El mapa reproducido a continuación sintetiza la disputa entre ambos países por el límite, ${ }^{4}$ desde la visión guatemalteca, y delinea el paralelo mencionado que se mantiene como división internacional hasta hoy día.

4 Rosa Torras Conangla, «Las fronteras en la historia: la construcción del límite entre Petén y Campeche», Espacios Políticos, vol. 11, n. 18 (2019): 5-20. 
Mapa 2. Mapa de la República de Guatemala (fragmento), 1895

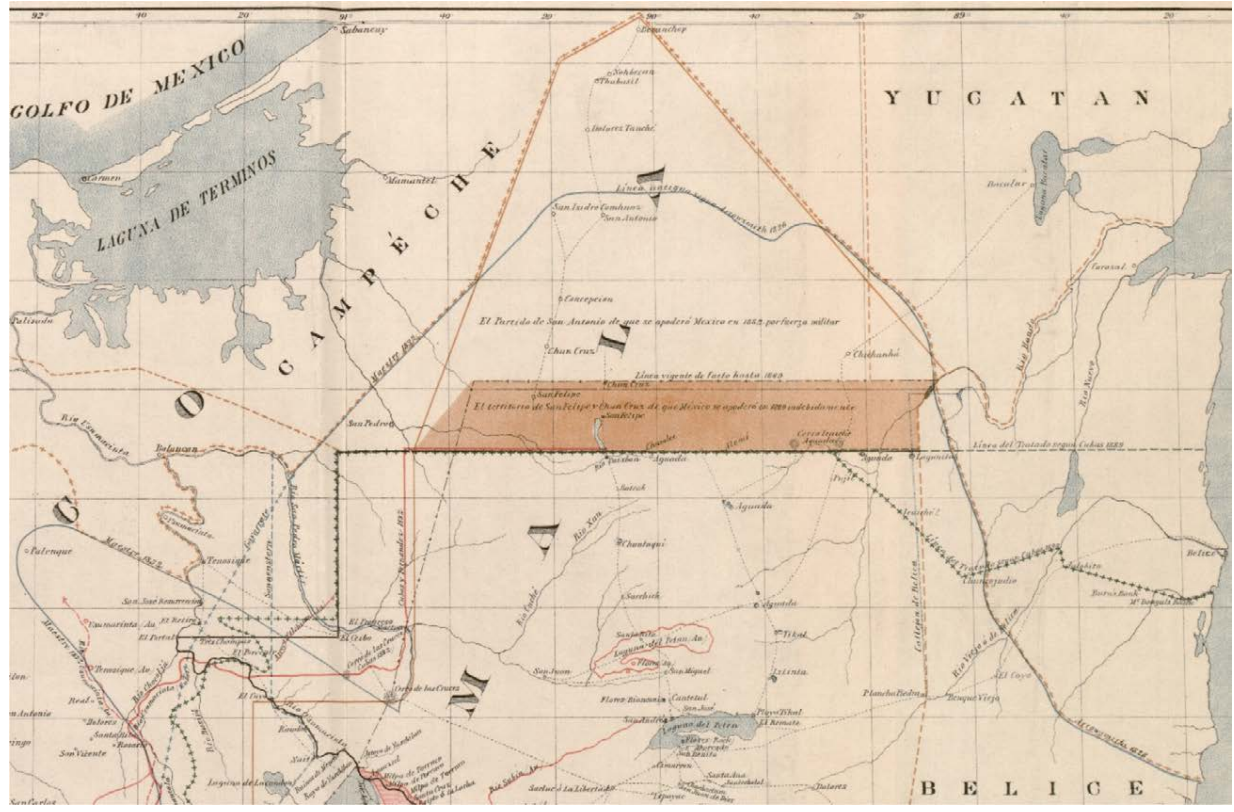

Fuente: «Map of the Republic of Guatemala» de Miles Rock, 1895, Library of Congress, https:// www.loc.gov/resource/g4811f.ct002031/.

El propósito de este artículo es reflexionar sobre la permanencia en la larga duración de la ideología colonial del asentamiento nuclear como otorgadora de derechos sobre el espacio selvático y sus recursos, dentro de un esquema económico extractivista y depredador. Sumando hallazgos propios y ajenos de investigación, propongo reflexionar sobre las dinámicas colonizadoras en una región transfronteriza la cual, desde la Colonia hasta finales de la década de los 80 del siglo XX, se ha caracterizado por una territorialidad en movimiento. Ello nos obliga a incluir en la discusión sobre pueblos indígenas aquellos procesos fuera de los pueblos, mucho más proclives a la mestización. ¿Cómo abrir nuestro concepto de territorialidad a tierras discontinuas y no delimitadas, a mares y aguas, a frutos del bosque? ¿Cómo salir analíticamente de la noción de pueblo de indios colonial?

A partir del análisis de la territorialidad sobre el mar de los kuna, Mónica Martínez ${ }^{5}$ nos ayuda a pensar sobre la territorialidad no como espacio acotado, sino como relación de los pobladores con el medio natural, y ello nos regresa a la concepción de territorios discontinuos propio de la noción de jurisdicción indígena. Si la estrategia colonizadora de la Corona hispana se basó en nuclear a

5 Mònica Martínez Mauri, «Cuando el territorio no es sólo tierra. La territorialidad y el mar kuna (Panamá)», en: Resistencia y territorialidad. Culturas indigenas y afroamericanas, (coord.) Javier Laviña y Gemma Orobitg (Barcelona, España: Publicacions i Edicions de la Universitat de Barcelona, 2008), 87. 
la población, los Estados-nación, ante la necesidad de competir por soberanía e integrar su propia unidad territorial, la reforzaron.

\section{La colonización de la selva a través del agua}

Un estudio previo sobre las modalidades de colonización en las selvas del sur de Campeche indicó cómo se fue estructurando una racionalidad colonial basada en la fragilización de las selvas. ${ }^{6}$ Dicha racionalidad se basó en un patrón de expansión territorial conformado por ciclos sobrepuestos de colonización extractiva cuyos frentes avanzaron a lo largo del siglo XIX desde Isla del Carmen, en el Golfo de México, tierra adentro hacia el Petén. Remontando los ríos que desaguaban en la laguna de Términos, grandes y medianos empresarios carmelitas ascendieron por sus aguas articuladoras de trasiegos de bienes y personas, al ritmo de la explotación maderera, adquiriendo tierras y asentando derechos de propiedad sobre grandes extensiones de selva, lo que les permitió extraer palo de tinte y maderas preciosas para exportar. Sobre ese tejido de alianzas políticas y estructura económica oligárquica se asentaron las grandes compañías estadounidenses extractoras de chicle, beneficiadas por las políticas de Porfirio Díaz.

Estamos, entonces, en un espacio decimonónico marcado por el impulso gubernamental de proyectos económicos extractivos articulados a las élites regionales, con una histórica movilidad de asentamientos humanos en condiciones de vida precarias, geoestratégicamente vital por estar situado en el límite con Guatemala. La élite carmelita, blanqueada por recién llegados procedentes de Europa y Estados Unidos atraídos por las políticas migratorias que los beneficiaban, consolidó en la región una estructura caciquil de rancheros criollo-mestizos que se movía entre una mayoría de población indígena y afrodescendiente. Dicha población local, rápidamente mestizada, habitaba dispersa en las selvas quedando enganchada, en condiciones de sujeción y explotación laboral, a las grandes unidades productivas ubicadas en las riberas de los ríos. Precariedad y movilidad fueron los atributos de la vida de cortadores y chicleros, por lo que la modalidad territorial impulsada por los gobiernos mexicanos, con la participación clave de las élites regionales, conformaron un territorio depredado y socialmente vulnerable. Sigo a Jean Revel-Mouroz, ${ }^{7}$ cuyo estudio sobre la colonización del trópico húmedo mexicano concluye que, si llamamos colonización a aquellos procesos encaminados a «poblar y desarrollar», la explotación forestal de carácter predatorio no coloniza pues genera poblamientos inestables con economías subalternas dependientes del exterior. El Estado moderno, como lo haría

6 Rosa Torras Conangla, Colonización y colonialidad en una selva de frontera. La cuenca campechana del río Candelaria (siglos XIX y XX) (Ciudad de México, México: UNAM, 2019).

7 Jean Revel-Mouroz, Aprovechamiento y colonización del trópico húmedo mexicano (Ciudad de México, México: Fondo de Cultura Económica, 1980), 13 y 316. 
el colonial, siguió penalizando la movilidad y la dispersión de asentamiento, aunque el sistema productivo lo estimulaba. Veamos cómo esa paradoja continuó operando con las políticas de reforma agraria del siglo XX.

El reparto agrario en las selvas del sur de Campeche tuvo muy poco impacto, a pesar de los esfuerzos de chicleros y pobladores por cumplir con los requisitos que marcaba la legislación agraria, ${ }^{8}$ pues dificultar el acceso a la tierra garantizaba disponibilidad de fuerza laboral para las grandes unidades productivas extractivas, alimentada por migraciones internas de campesinos procedentes del sursureste mexicano. Un inspector del Departamento de Trabajo, en 1939 analizaba así la situación:

Los Gobernadores del Territorio [de Quintana Roo] y el de Campeche son los que tienen el monopolio del chicle y con los productores del chicle de Yucatán. Estos desde 1935 son los negreros que están explotando a la gente y para poderlos explotar los han hecho que sean nómadas para que así los tengan seguros para el trabajo de cada año. ${ }^{9}$

En lugar de ello, en 1963 se aplicó el Programa de Colonización oficial, en la presidencia de Adolfo López Mateos, que impulsó un nuevo ciclo colonizador sobre las selvas que desconocía las demandas de los lugareños; esta vez se trataba de asentar a población campesina sin tierras procedente del norte de México, sobre todo de Coahuila, sobre la franja fronteriza con el Petén guatemalteco. Los ríos -binacionales- ya no bastaban para definir la dinámica territorial, sino que era necesario ocupar la franja de tierra colindante con Guatemala, marcada sobre el paralelo mencionado. La población local les llamaba, y sigue llamándolos, «los norteños»y son considerados, oficialmente, como los primeros colonos en llegar a esas selvas «eternamente vacías». Aunque los planes iniciales eran que se dedicarían a la agricultura, pronto se sumaron a la ola de ganaderización que iba ganando terreno en las selvas paulatinamente deforestadas. Asentados bajo la modalidad de Nuevos Centros de Población Ejidal, los objetivos marcados por el Plan de Colonización fueron «Reacomodar a los campesinos sin tierra, aumentar las producciones agrícola y ganadera y promover la creación de centros de población para evitar conflictos limítrofes con Guatemala», ${ }^{10}$ donde el apoyo estatal marca una diferenciación con los lugareños. La permanencia del constructo ideológico liberal del espacio vacio -heredero del despoblado colonial- parece constatarse, rompiendo una y otra vez las líneas de continuidad histórica creadoras de sentidos de pertenencia anclados en el tiempo. Pues si a lo largo del siglo XIX los colonos ideales eran los europeos y anglosajones, para

8 Ley de Ejidos de 1915; Código Agrario de 1934.

9 Archivo General de la Nación (Ciudad de México), Dirección General de Investigaciones Políticas y Sociales, caja 761, exp. 7, año 1939 , f s/n.

10 Maritoña Quiriarte Rodríguez, Chan-colona. Imagen del pasado, orgullo del presente (Campeche, México: Gobierno del estado de Campeche, 2009), 49. 
los gobiernos postrevolucionarios fueron los campesinos mestizos con referentes nacionales, dispuestos a arraigarse en las selvas y «mexicanizar» la frontera.

Esa política de transición de una sociedad forestal a una agraria y ganadera, basada en inmigrantes campesinos sin tierra, se vivía, paralelamente, del lado guatemalteco. Pero en ese caso, estos serían los sureños. No obstante, si bien los norteños fueron asentados para asegurar el límite internacional sobre el paralelo $17^{\circ} 49^{\prime}$, la colonización oficial guatemalteca con sureños se estableció en la mitad sur del Petén, fronteriza en sus extremos con el estado mexicano de Tabasco y con Belice, en las cuencas de los ríos Usumacinta y Hondo. Los sureños eran comúnmente conocidos también como milperos o macheteros, con una experiencia de vida de múltiples desplazamientos, ya fuera como colonos en las fincas de la costa sur guatemalteca o por migración forzada a causa del conflicto armado interno; todos con el anhelo vital de conseguir tierra.

Cabe mencionar, como apunte previo, que los primeros intentos republicanos de colonización del Petén tuvieron fechas muy tempranas. La primera disposición legal emanada de la recién estrenada República de Guatemala dirigida a colonizar las poco pobladas tierras peteneras debe situarse en $1834,{ }^{11}$ cuando la presidencia liberal de Mariano Gálvez emitió un decreto destinado a la colonización del departamento de Verapaz, que en estos tiempos incluía al Petén. Se trataba de «colonizar y poblar», en el sentido liberal de impulsar la explotación de las riquezas naturales de la región y de fomentar la inmigración europea vista como ideal para el desarrollo nacional; además de frenar el avance británico sobre Belice. Fueron varios los proyectos, todos fracasados, previos a la explotación chiclera en manos de compañías norteamericanas; todos, como lo haría igualmente México, con la intención de hacer llegar inmigrantes europeos o anglosajones que integraran la región al desarrollo nacional a través del blanqueamiento.

Pero volvamos a los tiempos de los sureños. Fueron varios los frentes colonizadores impulsados a partir de la década de los 60 para «desarrollar» el Petén, con distintas modalidades e intenciones, pero todos con la lógica agropecuaria. A nivel oficial, el proyecto más importante fue la Empresa Nacional de Fomento y Desarrollo del Petén (FYDEP), creada por decreto en 1959 y dominada por militares, la que instrumentó una colonización dirigida y, al mismo tiempo, abrió las puertas a la inmigración masiva y espontánea de campesinos indígenas y ladinos pobres provenientes del sur y del oriente de Guatemala, con necesidades de tierra y cultura totalmente agrícola muy distinta a la forestal tradicional petenera. ${ }^{12}$ También hubo frentes de colonización impulsados por la Iglesia, como el proyecto de cooperativas que organizaron los misioneros Maryknoll, en las márgenes de los ríos La Pasión y Usumacinta.

11 Ley $3^{\circ}$. Decreto de la Asamblea Legislativa de la República de Guatemala, de 29 de abril de 1834.

12 Margarita Hurtado Paz y Paz, Petén: ¿la última frontera? Construcción social de una región (Ciudad de Guatemala, Guatemala: FLACSO, 2010), 88-89 y 134. 


\section{Los propósitos del FYDEP eran impulsar:}

(a) el desarrollo económico integral y la integración territorial nacional; (b) la protección, administración y explotación de los recursos naturales y las tierras nacionales; (c) el incremento de la población: organización de colonias industriales, agrícolas y agropecuarias y fundación de nuevas comunidades urbanas y centros turísticos; (d) el mejoramiento de las condiciones económicas, sanitarias y culturales existentes, realización de obras y trabajos que contribuyeran a elevar el nivel de vida de los habitantes; y (e) el establecimiento de empresas industriales, agropecuarias y comerciales. ${ }^{13}$

En la colonización dirigida, su principal ideólogo, el coronel Oliverio Casasola y Casasola, dejaba bien claro a qué tipo de población iba destinada y qué grupos de población quedaban oficialmente excluidos:

La población maya no nos interesa como referencia. Evitemos complicaciones como los mayistas ortodoxos, elaborando cálculos sobre la población precolombina que se agrupó junto a Tikal y Uaxactún y otros centros de Petén [...] No deduzcamos de esos cálculos que al presente puede Petén acoger a millones de pobladores, porque esta idea absurda la hemos clasificado siempre dentro del casillero de Miserias de El Petén. [...] Gobernar es poblar, pero poblar con población sana, seleccionada y no con los contingentes nómadas que inhibieron hasta el presente al Norte del país el crecimiento demográfico y la selectividad étnica, siendo que la última es básica en toda experiencia de desarrollo. [...] por más simpatía que nos inspire el problema indígena, no es ese el contingente humano que reclama el proceso de Petén. ${ }^{14}$

Para el caso de la frontera con Tabasco, el gobierno guatemalteco en 1965 impulsó la instalación de asentamientos, en la modalidad de cooperativas, sobre la ribera del Usumacinta con el fin de evitar la construcción de presas proyectadas por México, que inundarían Petén. También eran campesinos sin tierra, esta vez expulsados por la modernización de la producción finquera de la costa sur guatemalteca. ${ }^{15}$ Como bien resume la investigadora Laura Hurtado, ${ }^{16}$ los programas de colonización impulsados por el Estado guatemalteco a lo largo de las décadas de 1960, 1970 y 1980 consistían en asentar migrantes en las selvas asumidas como «vírgenes», lo que debemos traducir, para esa época, como no incorporadas al régimen de propiedad legal del Estado. ${ }^{17} \mathrm{La}$ intencionalidad del

13 Ibíd., 89.

14 Oliverio Casasola y Casasola, Grandezas y miserias del Petén (Guatemala: Ediciones Indiana, 1968), 40-43.

15 Isabel Rodas Núñez, «El Estado, las instituciones y los frentes poblacionales en el noreste guatemalteco: el caso de los colonos del Usumacinta», Agricultura, Sociedad y Desarrollo, vol. 7, n. ${ }^{\circ} 2$ (2010), 143, http:// www.scielo.org.mx/scielo.php?script=sci_arttext\&pid=S1870-54722010000200002\&lng=es\&nrm=iso.

16 Laura Hurtado Paz y Paz, «Los programas de colonización y el Estado contrainsurgente en Guatemala», LiminaR. Estudios Sociales y Humanísticos, vol. 17, n. ${ }^{\circ} 2$ (julio-diciembre, 2019): 17, https://doi. org/10.29043/liminar.v17i2.677.

17 El departamento del Petén no entró en la Reforma Agraria promulgada en 1952 por el presidente Jacobo Árbenz, por lo que la política agraria de la que fue sujeto quedó marcada por los gobiernos militares que siguieron al derrocamiento de éste en 1954. La Reforma Agraria fue derogada y los campesinos despojados de las tierras que les habían sido adjudicadas, lo que generó fuerte presión en el agro. 
Estado era, al mismo tiempo que crear una válvula de escape a las regiones con alta demanda de tierras por parte de los campesinos como ocurrió en México, «poblar y asentar población en las regiones de frontera donde las élites económicas y militares se apropiaban de extensiones considerables para actividades agropecuarias y extractivas».$^{18}$ Con la apertura de la carretera entre Guatemala y Flores, en 1969, la llegada de migrantes se intensificó, pues abrió posibilidades de colonización más allá de aquellas marcadas por los ríos. Hurtado ubica dos flujos de población diferenciados: por un lado, los colonizadores que serían los ya mencionados sureños; por el otro, los q'eqchi'es huyendo de la explotación en las fincas de café del departamento de Alta Verapaz y que no fueron incluidos en los planes oficiales de colonización. ${ }^{19}$ Ambos grupos eran eminentemente agricultores, por lo que se estableció, como en el caso mexicano, una jerarquización de derechos en función del apoyo diferenciado del Estado. ¿Quiénes eran colonos, quiénes eran invasores? La racialización de ambas categorías, en el sentido de trato desigual en función de calidades socioculturales reales y atribuidas, seguía siendo notoria. Ya en la década de los 90, con las políticas conservacionistas, a la calidad de invasores se añadiría la de depredadores; pero dejaremos ese nuevo ciclo para futuras reflexiones.

\section{De la sociedad «nómada» a la «asentada»}

Retomemos la noción colonial de montaña y los anhelos de reducir a los indios montaraces del Petén Itzá, para plantear cómo operaron los atributos asociados a la movilidad de la población en el norte del departamento de Petén. Norman Schwartz nos recuerda que la mayoría de peteneros posteriores a la Conquista eran itzaes - asentados en el pueblo de San José junto con otros mayas y en parte del pueblo de San Andrés-, q'eqchi'es y mopanes - asentados en el pueblo de San Luis-, muzul procedentes de Belice y afrodescendientes que habían llegado a Belice. Además de ladinos y españoles asentados sobre todo en Flores, pues muchos de los españoles procedían de Campeche y Yucatán igual que los mayas yucatecos que se quedaron en el norte petenero.

Como quedó dicho, los distintos frentes de colonización, planificados o espontáneos, que llegaron durante la segunda mitad del siglo XX, se movieron por la mitad sur del departamento. El FYDEP marcó el paralelo $17^{\circ} 10^{\prime}$ como el límite norte a intervenir, de modo que excluyó de la colonización - finalmente ganadera - las selvas comprendidas entre este y el límite internacional con México, el paralelo $17^{\circ} 49^{\prime}$. Repartió tierras en nueve proyectos que ocuparon el $53 \%$ del total del territorio petenero, donde antes de ello solo existían

18 Laura Hurtado Paz y Paz, 26.

19 Megan Ybarra, «Petén, Guatemala, desde la colonización interna hacia la migración transnacional: ¿Nuevos paradigmas para el siglo XXI?», Ciencias Sociales y Humanidades, vol. 5, n. ${ }^{\circ}$ (2018): 57, https:// digi.usac.edu.gt/ojsrevistas/index.php/csh/article/view/634. 
71 fincas privadas legalmente inscritas en el Registro de la Propiedad Inmueble, las que representaban el $1 \%$ del total. ${ }^{20}$ En tiempos del chicle, era en la montaña donde se practicaba la economía extractiva con fuerza laboral asalariada que trabajaba para grandes compañías que operaban bajo el régimen de concesiones; diferenciada de los terrenos comunales cercanos a los pueblos reservados para la agricultura de subsistencia. A medida que se fueron instalando colonos y adjudicando tierras a grandes propietarios, los peteneros que no estaban acostumbrados a pelear por ellas, fueron trasladándose a la montaña para hacer sus milpas. Ante las quejas de que los colonos los estaban dejando sin tierras, de 1976 a 1980, el FYDEP otorgó ejidos a los doce municipios que integraban el departamento, todos ubicados al sur del paralelo $17^{\circ} 10^{\prime}$, pues las selvas del norte quedarían como parte de la Reserva de la Biósfera Maya, creada en 1990 mediante el Decreto n. ${ }^{\circ}$ 5-90. Sobre la pérdida de patrimonio por parte de los pueblos, pues los ejidos eran totalmente insuficientes, nos decía Schwartz a mediados de la década de 1990:

\begin{abstract}
A pesar del descontento existente, no hay constancia de que alguno de los antiguos asentamientos tenga la intención de presentar una demanda por la pérdida del patrimonio. Tampoco hay evidencia de que si el descontento se convierte en una demanda política articulada, ésta se base en términos de la comunidad, etnia o clase, términos conmutables en la cultura tradicional del Petén. La gente podrá hablar de apego al lugar, ascendencia maya o pobreza compartida, pero esto dependerá de lo que crea que llama más la atención de las autoridades del momento y tal vez reclame 500 caballerías — 22,500 hectáreas - o más, en vez del ejido de 250 caballerías - 11,250 hectáreas - concedido por el FYDEP. En el caso de que uno o varios asentamientos antiguos procedieran a reclamar viejos territorios, el proceso podría fortalecer la solidaridad comunal y revitalizar identidades étnicas que han sido olvidadas ocasionalmente. Sin embargo, dada la historia y estructura de poder en Guatemala, sería difícil que una comunidad recuperara lo que ha perdido. ${ }^{21}$
\end{abstract}

El investigador estadounidense anunciaba el rápido fin de la sociedad forestal, que él mismo nos explicó con maestría en su obra Forest Society. A Social History of Peten, Guatemala. Por de pronto, lo que hizo el FYDEP fue convertir el norte del Petén en reserva forestal y el resto lo privatizó; todo ello desconociendo las dinámicas territoriales que existían, ya fueran de asentamiento, de uso de los recursos naturales o de tenencia de la tierra. El FYDEP abrió un ciclo de colonización sobrepuesto al anterior como si, una vez más, las selvas del Petén fueran un espacio vacio, un despoblado. Así, como acertadamente afirmaba Schwartz en los noventa del siglo pasado, «aun cuando una

20 Mario Valdez Gordillo, Territorio y geopolítica: insurgencia y desmovilización en el Petén (1960-2000) (México: CESMECA, UNICAH, 2014), 95.

21 Norman B. Schwartz, «Reprivatización y privación: sistema tradicional y contemporáneo de tenencia de la tierra en el Petén, Guatemala», Mesoamérica, n. 29 (junio, 1995), 229-230, http://www.mesoamericarevista.org/publicacion29.htm. 
o dos comunidades pudieran recuperar sus antiguos terrenos, no hay manera de desenredar los últimos 30 años de historia».22

Caso especial es el de los q'echi', generalmente considerados migrantes al Petén desde finales del siglo XIX — a pesar de que parece haber fuentes coloniales que documentan su presencia en el sur del Petén- ${ }^{23}$ los cuales no son reconocidos como comunidad indígena autóctona de la región, sino vistos como grupo externo - simplificados bajo el apelativo de cobaneros $^{24}-\mathrm{y}$, como afirma el estudio de Megan Ybarra, a menudo como invasores. La investigadora plantea la paradoja —o perversidad — de diferenciar entre territorialidades indígenas aceptables - civilizadas y, por tanto, susceptibles de ser legalizadas- y otras que no lo son. Para su análisis utiliza el concepto colonialismo de asentamiento - Settler Colonialism - con el objetivo de explicar la diferenciación racializada que el Estado liberal estableció entre territorialidades y que, hoy día, se traduce en permitir que reclamen tierras únicamente aquellos indígenas que las poseen «desde tiempos inmemoriales». ${ }^{25} \mathrm{De}$ hecho, sabemos que la posesión desde tiempos inmemoriales fue argumento básico, y prácticamente el único posible, con el que contaban los pueblos indígenas para defenderse del despojo en los procesos de titulación de tierras decimonónicos. Constreñirse en su pueblo de indios, convertido en municipalidad en tiempos republicanos, fue la estrategia de defensa en los largos años de racionalidad liberal.

En este sentido, es interesante hacer notar cómo el historiador Edgar Esquit Choy, en su estudio sobre las expropiaciones de tierras que sufrieron los q'anjob'al con la Reforma Liberal de finales del siglo XIX, parte de la afirmación de que «la historia colonial española dio forma a los territorios comunales indígenas». ${ }^{26}$ Sabemos que la estructura colonial inició la ruptura de la territorialidad indígena basada en diversos pisos ecológicos complementarios espacialmente discontinuos, rematada por los procesos de desamortización decimonónicos contra los cuales la única defensa posible era argüir la territorialidad colonial. La capacidad de resistencia indígena al despojo, sumado a la necesidad de fuerza laboral disponible para las producciones hegemónicas, configuró al sujeto comunitario denostado por los regímenes liberales. Gustavo Palma ${ }^{27}$ nos recuerda que, tanto la racionalidad colonial como la liberal lo han protegido y estimulado en ciertos periodos históricos mientras que en otros ha buscado reducirlo y suprimirlo. El establecimiento de los pueblos de indios concibió y organizó a

22 Ibíd., 230.

23 José Alejos García, Adivinos del agua. Los itzaes en los discursos de identidad en Petén central (Ciudad de México, México: UNAM, 2010), 116.

24 Valdez Gordillo, 62.

25 Ybarra, 59.

26 Edgar Esquit, «El territorio indígena como espacio vacio: la expropiación de las tierras q'anjob’al a finales del siglo XIX», Estudios Interétnicos, vol. 25, n. 30 (2019), 22.

27 Gustavo Palma Murga, «Los cambiantes usos del territorio y la población en Guatemala en función de las racionalidades económicas hegemónicas: el caso de las tierras comunales», Territorios, n. ${ }^{\circ} 10$ (2015): 17-31. 
la población como comunidades con capacidad de reproducirse para sostener el régimen colonial lo que hasta la fecha, y con los cambios generados por la racionalidad liberal, ha situado a la población indígena y campesina en la condición de colonialidad en la que fueron ubicados desde ese momento histórico.

Ante esta realidad histórica ampliamente documentada, ¿cómo incorporamos al análisis los procesos vividos por la población «nómada»o «montaraz»?

El historiador Héctor Concohá Chet aporta un revelador estudio sobre los ajpajuyu'o pajuides, grupos de kaqchiqueles, que vivían autónomos en las montañas de San Juan Sacatepéquez, resistiendo a la reducción durante la Colonia y que ocuparon grandes espacios de tierra hasta finales del siglo XIX. Precisamente la traducción del término en español es «montañés», el cual se mantiene hasta hoy día con una connotación peyorativa que podríamos asociar más a «montaraz».

La separación y marginación que sufrieron los pajuides durante la época colonial persisten en la actualidad. [...] Están constituidos en aldeas y por ende son «aldeanos norteños». [...] En nuestro tiempo, entre los fenómenos estudiados que han sobrevivido cabe citar como ejemplo el caso de las personas que viven en las áreas urbanas de los pueblos y quienes todavía marginan de manera despectiva a los «pajuytecos». ${ }^{28}$

Se denomina pajuytecos, nos aclara Concohá, a los aldeanos de la parte norte del municipio kaqchiquel de San Juan Sacatepéquez, de ahí también nombrarlos como aldeanos norteños. Los pajuides, bautizados así por el arzobispo de Guatemala Cortés y Larraz, en la segunda mitad del siglo XVIII, para nombrar a los insumisos, fueron formados primero por población indígena a la que se le unió población ladina pobre; se establecían en cualquier lugar de las montañas, en kaqchiquel juyu'. Igual que toda la población no reducida en pueblos, poco aparecen contados en padrones, censos o registros. En el mismo sentido apunta Megan Ybarra, al analizar la situación de los q'echi' en el Petén cuando afirma que los nómadas no eran tomados en cuenta en los conteos de población, y de su inexistencia derivó que «Si los nómadas no tienen un territorio fijo y visible, tal vez no necesiten derechos sobre la tierra». ${ }^{29}$ Situación equiparable sería la que experimentaron los nombrados como escoteros en El Salvador y Guatemala coloniales, documentados por el historiador Juan Carlos Solórzano ${ }^{30}$ siguiendo a Cortés y Larraz, como aquellos grupos de familias huidas de los pueblos de indios que vivían dispersas en ranchos y completaban su subsistencia trabajando temporalmente en el añil, errando de plantación en plantación. De hecho

28 Héctor Concohá Chet, «El concepto de montañés entre los kaqchiqueles de San Juan Sacatepéquez, 15241700», en: La época colonial en Guatemala, estudios de historia cultural y social, (coord.) R. Herrera y S. Webre (Guatemala, Guatemala: Editorial Universitaria, 1998), 20.

29 Ybarra, 57.

30 Juan Carlos Solórzano Fonseca, «Haciendas, ladinos y explotación colonial: Guatemala, El Salvador y Chiapas en el siglo XVIII», Anuario de Estudios Centroamericanos, n. ${ }^{\circ} 10$ (1984): 107, https://revistas. ucr.ac.cr/index.php/anuario/article/view/25789. 
el vocablo escotero, según la Real Academia Española, refiere a persona que está libre, que viaja sin carga.

Por su parte, el término pajuide también es muy similar al de huite, utilizado en la primera mitad del siglo XIX para designar a aquellos mayas yucatecos que vivían dispersos y de forma autónoma en la montaña del oriente peninsular y que eran vistos como «bárbaros». ${ }^{31}$ El mismo Concohá apunta a la necesidad de hacer estudios comparativos entre poblaciones que, en diferentes espacios, tuvieron el mismo tipo de experiencia colonial y de qué modo ha permanecido la noción de asociar asentamiento disperso a «salvajismo».

Precisamente Isabel Rodas, en su estudio sobre la experiencia de colonización en las márgenes del río Usumacinta de la década de 1960, se encuentra con la paradoja apuntada al proponerse comprender si las categorías étnicas aplicadas comúnmente para clasificar a los grupos sociales en el territorio, daban algún sentido de pertenencia a las poblaciones que fueron producto de una modalidad distinta de colonización territorial al vivido desde la colonia española. De hecho, argumenta que los frentes poblacionales no han sido vistos en sus especificidades sino siempre bajo la categorización imperante, en tanto que población rural, de campesinos o indígenas. Afirma la antropóloga: «Oculto tras las nomenclaturas de indígenas o campesinos con arraigo a la tierra, el frente poblacional, como recurso cuyo valor reside en su condición de movilidad, no ha sido evidenciado como una realidad objetiva e histórica».32

$\mathrm{Y}$ es que, y aquí marcaría diferencias con el proceso institucional mexicano de ocupación de la frontera a partir de la conformación de Nuevos Centros de Población Ejidal, ni en los casos de proyectos de colonización planificados por el Estado guatemalteco con el mismo fin de fijar su soberanía frente al país vecino, las condiciones de asentamiento fueron suficientes para que la población no siguiera en desplazamiento, siempre en condiciones precarias que produjeron, a medida que escaseaba la tierra, choques entre migrantes. Constata Rodas que es la tensión residencia/desplazamiento como producto histórico determinado por el Estado patrimonialista la que marca las relaciones sociales en Petén y plantea definir un nuevo tipo de colectivo: los frentes poblacionales, entendidos como grupos de personas «que coinciden en algún momento en algún espacio, expulsados por esas dinámicas aldeanas, y que buscan un nuevo momento y lugar de inserción. Son colectivos efímeros y recurrentes». ${ }^{33}$ La pregunta sería, entonces, ¿qué relación tiene la identidad y dinámica de los frentes poblacionales con la territorialidad de quienes la Colonia catalogó de «montaraces»? Parece un crisol de subalternidades concatenadas que obliga a complejizar las herramientas de análisis.

31 Arturo Taracena Arriola, De héroes olvidados. Santiago Imán, los huites y los antecedentes de la Guerra de Castas (Ciudad de México, México: UNAM, 2013).

32 Rodas Núñez, 142.

33 Ibíd., 151. 


\section{A modo de balance: la paradoja de la colonización en el desarraigo}

En este rápido recorrido por los ciclos de colonización de las selvas transfronterizas que cubrían el sur de Campeche y Petén, vemos que permanece la estrategia de sobreponer territorialidades, al crear diferenciaciones desde criterios racializados de desigualdad entre grupos sociales. En este caso, funge como criterio básico el territorial, es decir, la relación del individuo con el medio natural a través del control de un espacio geográfico concreto. La historia colonial impuso el ideario de asociar territorio a espacio delimitado y continuo, como medio para controlar a la población y convertirla en fuerza laboral disponible; figura que adquirió su máximo esplendor con la formación de los Estados-nación en la óptica civilizatoria liberal.

Tomás Pérez Vejo señala que, para el caso de la República mexicana, la raza permanece como categoría hegemónica de análisis, al ser parte constitutiva del discurso de la modernidad en el que se basó la idea de nación. Permanencia que el ideario del mestizaje revolucionario redirigió hacia la existencia de grupos étnico-culturales más nacionalizadores que otros. ${ }^{34}$ En esa lógica ubicaríamos la llegada planificada de los norteños a las selvas de la cuenca del río Candelaria, al sur de Campeche, para asentarse sobre la línea divisoria con Guatemala y fijarla «de forma permanente»; en detrimento de reconocer la territorialidad dispersa del nómada lugareño. En el mismo sentido, Ramón González Ponciano ${ }^{35}$ recuerda que en los espacios donde el ensanchamiento de la frontera agraria coincide con la consolidación de la frontera nacional, como en nuestra región de análisis, la producción, el ambiente, las relaciones interétnicas y las identidades regional y nacional establecen una intensa relación con la geopolítica y la soberanía nacional.

Para el caso guatemalteco, la racialidad es todavía más evidente por la configuración de un Estado oligárquico con forma finquera, con un periodo de reforma agraria truncado en 1954 al que siguieron conatos de modernización al servicio del capitalismo, siempre con una fuerte militarización. Ello ha generado un enquistamiento de las demandas de tierra asociadas a la permanente reivindicación de los pueblos indígenas en contra de ese Estado excluyente. Dicho de otra manera, la legitimación de los reclamos de tierra se ha basado, a menudo, en la figura de la «posesión desde tiempos inmemoriales» la cual, en la mayoría de los casos, no puede más que basarse en la estructura colonial de pueblo de indios reapropiada como vehículo de resistencia y reivindicación territorial. Esta es la única vía legal posible; pero ¿no habría que reflexionar sobre sus implicaciones a nivel de colonialidad? Además,

34 Tomás Pérez Vejo, «Extranjeros interiores y exteriores: la raza en la construcción nacional mexicana», en: Inmigración y racismo. Contribuciones a la historia de los extranjeros en México, (coord.) Pablo Yankelevich (Ciudad de México, México: COLMEX, 2015), 89 y 120.

35 Jorge Ramón González Ponciano, «Frontera, ecología y soberanía nacional. La colonización de la franja sur de Marqués de Comillas», Anuario 1990 del Instituto Chiapaneco de Cultura (México: ICHC, 1991): 51, http://repositorio.cesmeca.mx/handle/11595/290. 
donde la figura de los pueblos de indios fue secundaria y se mantuvo por siglos una modalidad territorial dispersa repetidamente colonizada con inmigrantes en permanente desplazamiento, ¿cómo definir derechos territoriales?

Retomemos en este punto la propuesta de Shannon Speed, ${ }^{36}$ de aplicar el término colonialismo de asentamiento para entender la permanencia de las dinámicas coloniales en los Estados latinoamericanos. La antropóloga reconoce que las propuestas de colonialismo interno y colonialidad aportan herramientas válidas para entender la naturaleza colonial de las relaciones de poder en los Estados creados tras su independencia política de la Corona española; pero se quedan en concebir esas dinámicas coloniales como residuales o legados del pasado colonial y no como la esencia misma de la configuración de estos Estados-nación. Habrá que ver si el matiz nos permite debatir con mayor profundidad sobre los marcos mentales que operan en nuestros análisis - inquietud que es básica en la propuesta decolonial liderada por Aníbal Quijano-. De momento, tratar de explicar el complejo mundo territorial de una región de refugio y, por ello, permanentemente sujeta a colonización, genera más preguntas que respuestas. ¿Qué tanto nuestra noción de territorialidad está impregnada de la idea de espacio acotado, confinado?, ¿qué tanto la noción liberal de límite - heredera del lindero colonial — ha impregnado nuestra idea de territorialidad?, ¿qué tanto hemos interiorizado el despoblado?

Megan Ybarra sostiene:

[...] los guatemaltecos usan la noción de colonización y asentamiento para referirse exclusivamente a la residencia y a la agricultura. Si bien esto tiene sentido en términos de despojo colonial, esto contradice las prácticas conocidas de los pueblos indígenas que han conocido partes de Petén como regiones de refugios para la caza, la pesca y el chiclero antes y durante la colonización [...] parece reproducir[se] la idea de que los pueblos indígenas solo pueden reclamar tierras que han poseído desde tiempos inmemoriales. ${ }^{37}$

Pues destruir para reemplazar es la lógica de continua colonización entendida desde la ideología del espacio vacio que, permanentemente, sobrepone ciclos desconociendo los anteriores. El capitalismo en el que se formaron los Estados-nación latinoamericanos y el neoliberalismo posterior mantienen la misma configuración bajo imperativos de desposesión/extracción/eliminación justificados desde lógicas racializadoras. Ello, en un medio como el trópico húmedo tan rico en recursos naturales como frágil, donde los impulsos estatales fueron y siguen siendo motores de lo que el geógrafo Carlos Reboratti ${ }^{38}$

36 Shannon Speed, «Structures of Settler Capitalism in Abya Yala», American Quarterly, vol. 69, n. 4 (diciembre, 2017): 783-790, https://doi.org/10.1353/aq.2017.0064.

37 Ybarra, 63 y 61.

38 Carlos E. Reboratti, «Fronteras agrarias en América Latina», Geo-Crítica, n. ${ }^{\circ} 87$ (mayo, 1990), http:// www.ub.edu/geocrit/geo87.htm. 
denomina frontera hueca, entendida como aquella que es movilizada por la economía y no por el impulso social. Para el caso que nos ocupa, el modelo económico extractivo y depredador quiebra el impulso social al producir conflictos y vulnerabilidades, mientras genera imaginarios excluyentes.

Finalmente, repensar las continuidades del proyecto colonial nos obliga a adentrarnos en el complejo mundo de las legitimidades basadas en los procesos históricos a los cuales articular las reivindicaciones presentes. En materia de derechos territoriales de los pueblos originarios, cabe identificar aquellas modalidades inherentes a la propia noción de pueblo colonial reformuladas desde el ideario liberal nacionalista que, permanentemente, excluye, aunque utiliza, a hombres y mujeres montaraces.

\section{Bibliografía}

Alejos García, José. Adivinos del agua. Los itzaes en los discursos de identidad en Petén central. Ciudad de México, México: UNAM, 2010.

Casasola y Casasola, Oliverio. Grandezas y miserias del Petén. Guatemala: Ediciones Indiana, 1968.

Concohá Chet, Héctor. «El concepto de montañés entre los kaqchiqueles de San Juan Sacatepéquez, 1524-1700». En: La época colonial en Guatemala, estudios de historia cultural y social, coordinado por Robinson Herrera y Stephen Webre, 19-41. Guatemala, Guatemala: Editorial Universitaria, 1998.

Esquit, Edgar. «El territorio indígena como espacio vacio: la expropiación de las tierras q'anjob'al a finales del siglo XIX». Estudios Interétnicos, vol. 25, n. ${ }^{\circ} 30$ (2019): $15-42$.

González Ponciano, Jorge Ramón. «Frontera, ecología y soberanía nacional. La colonización de la franja sur de Marqués de Comillas». Anuario 1990 del Instituto Chiapaneco de Cultura, (México, ICHC, 1991), 50-83.

González Ponciano, Jorge Ramón. «Frontera, ecología y soberanía nacional. La colonización de la franja sur de Marqués de Comillas». Anuario $1990 \mathrm{del}$ Instituto Chiapaneco de Cultura, (México: ICHC, 1991): 50-83. http:// repositorio.cesmeca.mx/handle/11595/290.

Hurtado Paz y Paz, Laura. «Los programas de colonización y el Estado contrainsurgente en Guatemala». LiminaR. Estudios Sociales y Humanísticos, vol. 17, n. ${ }^{\circ} 2$ (julio-diciembre, 2019): 15-31. https://doi.org/10.29043/liminar. v17i2.677.

Hurtado Paz y Paz, Margarita. Petén: ¿la última frontera? Construcción social de una región. Ciudad de Guatemala, Guatemala: FLACSO, 2010.

Machault, Julien. «Organización y modalidad del intercambio a larga distancia en "la Montaña" del Petén, siglos XVI-XVII». Indiana, vol. 35, n. ${ }^{\circ} 1$ (2018): 97-100. http://dx.doi.org/10.18441/ind.v35i1.97-120. 
Martínez Mauri, Mònica. «Cuando el territorio no es sólo tierra. La territorialidad y el mar kuna (Panamá)». En: Resistencia y territorialidad. Culturas indigenas y afroamericanas, coordinado por Javier Laviña y Gemma Orobitg, 85-104. Barcelona, España: Publicacions i Edicions de la Universitat de Barcelona, 2008.

Okoshi Harada, Tsubasa. «De lo ajeno impuesto a lo nuestro fundado: el proceso de "domesticación" del espacio en los pueblos indios de la gobernación de Yucatán». En: Recorriendo el lindero, trazando la frontera, coordinado por Tsubasa Okoshi Harada, et al., 15-35. Ciudad de México, México: UNAM, 2018.

Palma Murga, Gustavo. «Los cambiantes usos del territorio y la población en Guatemala en función de las racionalidades económicas hegemónicas: el caso de las tierras comunales». Territorios, n. ${ }^{\circ} 10$ (2015): 17-31.

Pérez Vejo, Tomás. «Extranjeros interiores y exteriores: la raza en la construcción nacional mexicana». En: Inmigración y racismo. Contribuciones a la historia de los extranjeros en México, coordinado por Pablo Yankelevich, 89-124. Ciudad de México, México: COLMEX, 2015.

Quiriarte Rodríguez, Maritoña. Chan-colona. Imagen del pasado, orgullo del presente. Campeche, México: Gobierno del estado de Campeche, 2009.

Reboratti, Carlos E. «Fronteras agrarias en América Latina». Geo-Crítica, n. ${ }^{\circ} 87$ (mayo, 1990). http://www.ub.edu/geocrit/geo87.htm.

Revel-Mouroz, Jean. Aprovechamiento y colonización del trópico húmedo mexicano. Ciudad de México, México: Fondo de Cultura Económica, 1980.

Rocher Salas, Adriana. «La vicaría de Chichanhá y la provincia franciscana de San José de Yucatán». En: Arte e historia en el sur colonial de Quintana Roo, siglos XVI-XVIII, coordinado por Juan Manuel Espinosa Sánchez, 97-108. México: CONACULTA; Secretaría Cultura Quintana Roo; Plaza y Valdés, 2011.

Rodas Núñez, Isabel. «El Estado, las instituciones y los frentes poblacionales en el noreste guatemalteco: el caso de los colonos del Usumacinta». Agricultura, Sociedady Desarrollo, vol. 7, n. ${ }^{\circ} 2$ (2010), 137-154. http://www.scielo.org.

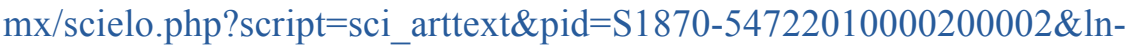
$\mathrm{g}=\mathrm{es} \& \mathrm{nrm}=$ iso.

Schwartz, Norman B. «Reprivatización y privación: sistema tradicional y contemporáneo de tenencia de la tierra en el Petén, Guatemala». Mesoamérica, 29 (1995): 215-232.

Schwartz, Norman B. «Reprivatización y privación: sistema tradicional y contemporáneo de tenencia de la tierra en el Petén, Guatemala». Mesoamérica, n. ${ }^{\circ} 29$ (junio, 1995), 215-232. http://www.mesoamericarevista.org/ publicacion29.htm.

Schwartz, Norman B., Forest Society. A Social History of Peten Guatemala. EUA: University of Pennsylvania Press, 1990. 
Solórzano Fonseca, Juan Carlos. «Haciendas, ladinos y explotación colonial: Guatemala, El Salvador y Chiapas en el siglo XVIII». Anuario de Estudios Centroamericanos, n. ${ }^{\circ} 10$ (1984): 95-123. https://revistas.ucr.ac.cr/ index.php/anuario/article/view/25789.

Speed, Shannon. «Structures of Settler Capitalism in Abya Yala». American Quarterly, vol. 69, n. ${ }^{\circ} 4$ (diciembre, 2017): 783-790. https://doi. org/10.1353/aq.2017.0064.

Taracena Arriola, Arturo. De héroes olvidados. Santiago Imán, los huites y los antecedentes de la Guerra de Castas. Ciudad de México, México: UNAM, 2013.

Torras Conangla, Rosa. «Las fronteras en la historia: la construcción del límite entre Petén y Campeche». Espacios Políticos, vol. 11, n. ${ }^{\circ} 18$ (2019): 5-20.

Torras Conangla, Rosa. Colonización y colonialidad en una selva de frontera. La cuenca campechana del río Candelaria (siglos XIX y XX). Ciudad de México, México: UNAM, 2019.

Valdez Gordillo, Mario. Territorio y geopolítica: insurgencia y desmovilización en el Petén (1960-2000). México: CESMECA, UNICAH, 2014.

Ybarra, Megan. «Petén, Guatemala, desde la colonización interna hacia la migración transnacional: ¿Nuevos paradigmas para el siglo XXI?». Ciencias Sociales y Humanidades, vol. 5, n. ${ }^{\circ} 1$ (2018): 55-66. https://digi.usac.edu. gt/ojsrevistas/index.php/csh/article/view/634. 